\title{
A HIGH-POWER Ka-BAND FREE-ELECTRON MASER, DEFINED BY A 2D - 1D BRAGG LASING CAVITY
}

\author{
Philip MacInnes, Ivan V. Konoplev, Adrian W. Cross, \\ Wenlong He, Helen Yin, Colin G. Whyte, Craig W. Robertson, \\ Kevin Ronald and Alan D. R. Phelps. \\ SUPA Department of Physics, University of Strathclyde, \\ Glasgow, Lanarkshire, Scotland
}

One of the on-going research programs, at the University of Strathclyde, involves the development of high-power, pulsed, Free-Electron Masers (FEMs) with the lasing cavity defined using periodic corrugations on the drift-tube walls ${ }^{1-4}$. These corrugations form 1D and 2D Bragg resonators, whose reflection bands determine the dominant resonance of the maser ${ }^{5}$. Proper selection of the FEM undulator magnetic field strength, allows for efficient extraction of energy from a mildly relativistic $(400-500 \mathrm{keV})$ electron beam at the resonant frequency of the lasing cavity, leading to monochromatic output at power levels of several tens of megawatts and pulse durations of $\sim 150 \mathrm{~ns}$ (determined primarily by the pulse duration of the driving power supply of 250ns).

This paper presents the results from the current iteration of the FEM experiment, which utilizes a 2D Bragg input mirror, coupled with a 1D Bragg output mirror ${ }^{4}$. Single frequency operation is demonstrated, as is a degree of tunability, via variation in the undulator magnetic field strength. The experimental results are compared with numerical and analytical studies.

1. A. W. Cross et al., "Experimental and theoretical study of 2D Bragg structures for a coaxial free electron maser", Nuclear Instruments and Methods in Physics Research A, 2001, pp. $164-172$.

2. A. W. Cross et al., "Experimental studies of coaxial twodimensional Bragg structures for a high power free electron maser", Applied Physics Letters, 8(9), 2002, pp. 1517 - 1519. 3. I. V. Konoplev et al., "Experimental and theoretical studies of a free electron maser based on two-dimensional distributed feedback", Physical Review E, 76, 2007, article: 056406.

4. I. V. Konoplev et al., "High current electron Beams for high power free electron masers based on two-dimensional periodic lattices", IEEE Transactions on Plasma Science, 38(4), 2010, pp. $751-763$.

5. N. S. Ginsburg et al., "mode competition and control in free electron lasers with one and two dimensional Bragg resonators", Nuclear Instruments and Methods in Physics Research A, 375, 1996, pp. $202-206$. 